\title{
Semantic Differential as an Assessment Tool of (Dis) Advantages of QMS in the Light of Accredited Certification in Poland*
}

\author{
Katarzyna Hys, Liliana Hawrysz \\ Opole University of Technology, Opole, Poland
}

\begin{abstract}
This article is a continuation of the issue in the field of assessment of (dis)advantages resulting from the implementation of the quality management systems (QMS) in a structure of the organization. The publication uses the results of studies conducted in the range of assessment's information completeness provided by the certification bodies (CBs) in the context of advantages and disadvantages of the QMS implementation in accordance with PN-EN ISO 9001. In addition, an attempt to define a tool for the QMS assessment of (dis)advantages in the organization has been made. The basis for empirical analysis of the issue was the information provided by an accredited management systems CBs recommended by the Polish Centre for Accreditation (PCA). There are 33 units in Poland, which were granted by PCA with the accreditation within the range of ISO 9001:2008. In the first stage of the research work, a substantive analysis of websites content among mentioned CBs has been carried out. In addition, the paper proposes use of semantic differential method (SD) to evaluate (dis)advantages of the QMS. SD adaptation for the assessment of the QMS (dis)advantages is the authorial concept. The authors hope for polemic in this area. In the face of obtained results, an authorial SD construction has been proposed, which is useful and may help in the formulation and conveying of the relevant (reliable) information to potential clients in the range of (dis)advantages resulting from the QMS implementation to the organization. As a consequence, the recommendations have been set, which are kind of guidelines that could significantly influence the realignment of the information state conveyed on the internet by the CBs.
\end{abstract}

Keywords: quality management system (QMS), accredited units, (dis)advantages form the QMS implementation, semantic differential (SD)

\section{Introduction}

Quality management system (QMS), especially ISO $9000: 2008$, in European conditions permanently took root in minds of the decision-makers as a tool supporting the management of an organization (The ISO Survey). The consequence of this state is widespread use of the standard or its components in an organizational practice. Admittedly, the emphasis here is on the process of management identification, implementation, and improvement,

\footnotetext{
* Acknowledgments: This paper was supported from Research Project by National Science Centre, No. 2011/01/B/HS4/04796. Katarzyna Hys, Ph.D., Production Engineering and Logistics Department, Opole University of Technology.

Liliana Hawrysz, Ph.D., Economics and Management Department, Opole University of Technology.

Correspondence concerning this article should be addressed to Katarzyna Hys, 76 Prószkowska St., 45-758 Opole, Poland. E-mail: k.hys@po.opole.pl.
} 
especially operational, in the aspect of concentration on quality in each level of the organization's functioning. However, it also serves the processes creation of an organization's reality through this quality. In practice, this means that they contribute to the changes. What is important is the mentality of employees which in the long term affects positively the efficiency and effectiveness of actions taken by the organization. However, basic conditions concerning: purposefulness of implementation, feasibility, measurability, consistency and consequence of taken actions, commitment, flexible responsiveness, and openness to the evolution of action in the context of improvement processes must be fulfilled. Then, the validity of QMS implementation can be analyzed and (dis)advantages of this implementation can be determined.

\section{Methodology}

Literature analysis of the issue of (dis)advantages resulting from the QMS implementation in the organizational structures allowed for an initial observation. Although the authors of the publication on the ISO 9000:2008 standard write broadly on the assets of the system, the aspect of potential weaknesses or threats is described quite laconically or completely ignored (Kowalczyk, Jabłoński, \& Wawak, 2013). Therefore a basic question suggests itself: Is the ISO standards implementation risk free? Are all of the implementations completed with full success in the opinion of the decision-makers in the companies? Making an in-depth analysis of the issue, one could probably multiply questions of a similar tint. However, anybody who thinks reasonably, especially the decision-maker, would response rather skeptically to similar sets of optimistic scenarios. Although they are possible and by all means real, there are also the opposite scenarios, more pessimistic, which seem to take into account realities of the organization functioning in the market. In connection with the above, an analysis of web content information of CBs accredited by PCA in Poland has been carried out, in terms of complexity of content provided to potential clients in the range of potential (dis)advantages resulting from the QMS implementation in the structure of an organization.

Currently, the website includes a list of $33 \mathrm{CBs}$ that are accredited by PCA in the PN-EN ISO 9001. As a result of the basic analysis of the information contained in service offers of the above-mentioned units, it was found that out of 33 units, only 13 took up in their descriptions the issue of (dis)advantages resulting from the possession of the certificate of the system conformity with ISO $9000: 2008$ standard. Moreover, it has been determined that the offer of these institutions, addressed to clients, included only indicated benefits of systems certification. However, there is no internalization and demonstration of potential risks and disadvantages which are the results of improper preparation or process of certification in enterprises. Experience in many aspects of life indicates that the awareness and knowledge of potential mistakes and risks that may arise during its implementation can activate the state of particular vigilance of employees responsible for the implementation process in the organization and may allow to avoid making the classic mistakes. Therefore it is important for entrepreneurs to have the possibility to obtain comprehensive and reliable information before beginning the implementation process of the system in their structure. This situation could be benefit entrepreneurs, who taking the effort (economic and non-economic) of preparation of the organization for the necessary changes could take protective measures of those elements of the process, which require special security at the planning stage of the implementation process.

\section{Hypothesis}

On the basis of this situation, main and auxiliary hypotheses have been defined for the problem 
(Brzeziński, 2005) which is: Is the information provided on websites by CBs, accredited by PCA, concerning (dis)advantages from the implementation of the ISO 9001 system complete? Hypotheses have been described as follows:

Main Hypothesis: Information provided on the websites by CBs accredited by the PCA, concerning (dis)advantages of ISO 9001 implementation allows entrepreneurs to prepare properly for the QMS implementation in terms of organization.

Auxiliary hypotheses:

H1: Data transmitted by the CBs on the websites contain information about the benefits (opportunities and possibilities) of the QMS implementation in the structures of the organization.

H2: Data transmitted by the CBs on the websites contain information about disadvantages (risks and errors) of the QMS implementation in the structures of the organization.

For hypothesis defined in this way, a verification process has been carried out through the analysis of the information content published on the websites of the CBs.

\section{Research Method-Empirical Analysis of the Issues}

Verification of hypotheses from a practical point of view is based on an analysis of issues based on two types of variables (Giddens, 2004): dependent and independent. For the described situation, the independent variable is the information provided by the $\mathrm{CBs}$ on their websites, while the dependent variable is the completeness of the information in the context of (dis)advantages of ISO system implementation in the structure of organization.

On the basis of analysis of CBs' web content in the context of information on (dis)advantages, only 128 features indicating benefits of implementing ISO 9001 were accumulated. Among listed attributes, one can mention those, which existence is single or repetitive (Hys \& Hawrysz, 2012). All collected attributes, with regard to the merit, can be divided into specific thematic groups. And so, distinguished were the issues showing primarily the effects of management, in particular financial and organizational. Furthermore, the results were indicated depending on the subject of analysis, i.e., in relation to competitors, employees, and clients. Demonstrated results have a high level of attractiveness in manager's assessment. Thus, in the case of any reasonable entrepreneur, the aspect of ISO system implementation should be indisputable, or at least considered. During analysis of data, an attention should be paid to the assignment of characteristics to the individual thematic groups. The division was made on the basis of semantic tone and character of a particular feature, nevertheless the authors are aware that due to the way of data collection, the system may provide a basis for further scientific polemics. However, it is worth noting that the assumed thematic sets are a logical layout of interrelated features, forming a sequence of cause and effect. However, a certain trend can be noticed - this system can be described in classical terms of management (Stoner, Freeman, \& Gilbert, 2001). Where the basis of action is planning activities, then their organization at the strategic, tactical, and operational level motivates interested parties (mainly employees and clients) and controls or monitors the effectiveness of taken actions.

\section{Hypotheses Verification}

The analysis of the content of information published on the website by the CBs in the field of information about (dis)advantages of the QMS implementation according to ISO 9001 has allowed verifying the hypotheses. 
Hypothesis number one: Data provided by the CBs on websites contain information about the benefits (opportunities and possibilities) of the QMS implementation in the structure of organization. As a result of analysis of the information published on the websites of these units 128, properties have been set. All the characteristics indicate only the benefits of implementation, the ISO 9001 system in corporate structure, including market opportunities and possibilities of organization's internal development. Mentioned benefits relate primarily to the effects of management, including financial and organizational, as also to competitors, employees, and clients. Therefore it can be concluded that the first hypothesis was verified positively. In consequence of above, the situation concerning verification of the second hypothesis, i.e. data provided by the CBs on websites contain information about disadvantages (threats and errors) of the QMS implementation in the structure of organization, means that this hypothesis was verified negatively. In fact there is no information about the potential risks resulting from improper approaches or the realization of process of system implementation (erroneous preparatory actions, preliminary, executive or pro-implementation actions). Not forwarded is also information concerning consequences resulted from improper implementation of the quality management system. Improperly carried-out implementation process is a serious risk to potential entrepreneurs. In fact it may expose them to unnecessary costs or losses of a financial and non-financial character (including moral). Moreover, it exposes workers to frustration and demotivates to make efforts related to the QMS. In consequence of the above, it can be concluded that the information reported by CBs is incomplete. They are a kind of an allurement for potential entrepreneur, targeting and focusing his attention solely on the benefits of system implementation - which has no confirmation in real conditions. Commonly used record of (only) benefit from the QMS implementation is so attractive, which is unbelievable. The effects of taken actions and incomplete descriptions the entrepreneur usually interested in consider to be unreliable, which in turn is not beneficial for the CBs, concluding: It might be indicated that the information on the QMS implementation in the organization structures can be described with a help of categories, that can be collected in the following associative sequence: assumptions-dilemmas-interpretations, which in practice means expectations-(dis)advantages-interpretations of an entrepreneur in the field of the QMS implementation. Consequently, it can therefore be assumed that taken issue as well as concepts set limits of reflection characteristic for that issue.

\section{Structure of Model}

In the context of the above, where a total dissonance has been shown between the range of information provided by $\mathrm{CBs}$ and expected by the decision makers for identification and preparation for the QMS implementation in the environment of organization, a tool supporting comprehensive preparation of information in this regard will be offered.

The reference here is to the use of SD (Osgood, Suci, \& Tannenbaum, 1957). It is a way of exploring the deep structure of words, consisting of subjective assessment of impressions on assessed object in the adopted scale using the defined questionnaire. In the assessment questionnaire, respondents in a way review subjectively their attitude, i.e., the attitude (Obuchowski, 1972; Mika, 1981; Nowak, 1973; Mądrzycki, 1977; Prężyna, 1967; Gołaszewska, 1964; Hys, 2013a; 2013b; Hawrysz \& Hys, 2013) in relation to the assessed object. The attitude (Hilgard, 1967), as a category, is a positive or negative respond to some objects, concepts, or situations as well as the willingness to react in a predetermined manner to these (or related to them) objects, concepts, and situations. It is worth noting that attitudes are formed by the interaction of the individual and its 
environment. It is important to be aware of distinguishing components of attitudes. According to psychologists (Prężyna, 1975; Newcomb, Turner, \& Converse, 1970; Bielecki, 1986), attitudes are created on the basis of:

- Acquired knowledge and experiences, which is so called cognitive aspect (attitude is defined here as a system of evaluative perceptions);

- Emotions that are manifested in the likings and preferences of the respondents. It is so called motivational aspect, which means a certain state of readiness for the appearance of the activity motive;

- Behaviors or behavioristic element which affect the actions taken throughout the process of purchase realization and mean similarity of occurrence of a particular behavior in a given situation (Prężyna, 1967).

The immanent evaluation feature is that it is always carried out with the same number of the opposing terms placed on the two poles of scale. In practice, it means that, for the evaluated object, antagonistic pairs of statements are defined (pairs of antonyms, usually adjectives), for which the grading scale has been determined. A kind of continuum is formed to which a certain number corresponds and generally used is the scale of which the central assessment takes a neutral form. It is worth noting that the intervals among particular assessments values are of an equal length. The task of the respondent is to select one category on each assessment scale. Assessment of attitudes is made in the range: extremely positive attitude - an attitude decidedly negative. Thanks to that, the assessment level can be measured using various scales, especially ordinal scale. In real conditions, a measurement using the SD lies in the fact that a set of several ordinal scales, mostly seven degree or nine point, is placed in the questionnaire. These scales are independent of each other. The respondent giving the answers must mark out only one category on each scale.

Analysis of the literature on the practical application of SD in empirical research has shown that one usually takes a specific layout template in the assessment questionnaire. This means that in a given column, at the discretion, only positive characteristics are defined, and in the opposite column only negative characteristics. It is widely used, however according to Babbie (2003), in order to avoid loads in the patterns of responses, custom records should be applied, enabling an intellectual effort during the assessment process. As far as the analysis of collected data aspects, accepted method of inference is determined by the conditions of the study, accepted hypothesis, and their verification methods, which mean that the analysis can be carried out in various ways. But most often so called profile analysis is used, consisting in drawing a graphic profile for comparable characteristics. Profile is formed by joining with a line numerical values obtained during the measurement for each of the characteristics from evaluation scales. During the analysis, it is supposed that ordinal scales ranges are equal. Then specific values are assigned to scale ranges, the so-called weights. Usually these are numbers from one to seven or from -3 to +3 . Obtained results can be analyzed using basic statistical characteristic such as the arithmetic mean, weighted average, and standard deviation from these averages or the medians. Given characteristics are calculated for all pairs of measured evaluative characteristics. Collection and reduction of data consist in therefore counting all filled in scales in the questionnaire, classifying them and presenting the results in a statistical series. Obtained averages are usually joined with lines on combined scales formed from assigned weights. Then a profile graph arises — specific for a particular phenomenon.

\section{Analysis by Means of SD}

Using obtained results of the analysis concerning the verification of adopted hypotheses, an attempt to construct a questionnaire used to define the model evaluation of the QMS (dis)advantages has been made. The following stages of building a semantic scale have been identified: 
- Transformation of characteristics obtained in the study and analysis of the substantive content of websites of CBs in Poland accredited by PCA. Selection of test objects fulfilling the role of stimuli affects the respondent (the name of characteristics, which form an arranged list of (dis)advantages resulting from the QMS implementation).

- Determination of opposite pairs of terms (usually adjectives) describing tested object and corresponding the dimensions of the semantic space (the basis here is the assessment level given to each tested characteristics).

- Development of responses patterns - the scale expressed as a set of bipolar scales estimated, sustainable, seven point, at the end of which there are categories of responses.

It is worth noting that the following assumption has been made: Each evaluated object is evaluated independently. While constructing an assessment questionnaire, taxonomy of characteristics obtained during the verification of the substantive content of web sites of CBs accredited by PCA has been used. All collected attributes, with regard to the merit, can be divided into specific thematic groups.

\section{The Effects of Modeling}

While defining a model of assessment of (dis)advantages resulting from the QMS implementation, it has been determined that: SD scale consists of six thematic groups, i.e., concerning: the effects of the enterprise management (see Table 2), organizing activities in the enterprise (see Table 3), financial aspects (see Table 4), competition (see Table 5), employees (see Table 6), and clients (see Table 7). SD model takes therefore the following form. Forty-two pairs of antonyms have been defined in the range of six defined thematic groups. Each pair of the opposing statements is assessed in bipolar seven point scale. The meaning of used weights is as follows: (3) definitely yes (extremely positive); (2) yes; (1) rather yes; (0) I do not have any opinion (neutral); (-1) rather no; (-2) no; (-3) definitely no (extremely negative). All one needs to do is to select the level of subjective assessment according to the key used on the scale and to join obtained grades. As a result, a semantic profile arises for the tested characteristics (see Table 1).

Table 1

An Example of an Assessment's Questionnaire by Means of SD

\begin{tabular}{|c|c|c|c|c|c|c|c|c|}
\hline \multirow[t]{2}{*}{$\begin{array}{c}\text { Characteristics } \\
\text { negative/positive grades }\end{array}$} & \multicolumn{7}{|c|}{$\begin{array}{c}\text { Grades } \\
\text { meaning of importance in accordance with } \\
\text { accepted values }\end{array}$} & \multirow[t]{2}{*}{$\begin{array}{c}\text { Characteristics } \\
\text { negative/positive grades }\end{array}$} \\
\hline & -3 & -2 & -1 & 0 & 1 & 2 & 3 & \\
\hline Positive overtone characteristic & & & • & & & & & Characteristic's antonym \\
\hline Characteristic's antonym & & & & & & & & Positive overtone characteristic \\
\hline Negative overtone characteristic & & & & & & & & Characteristic's antonym \\
\hline Characteristic's antonym & & & & & & & - & Negative overtone characteristic \\
\hline$\ldots$ & & & & & & & - & $\ldots$ \\
\hline
\end{tabular}

Note. Source: Own study.

Technical note: The questionnaire can additionally be marked with colors to enhance the effect of reception. For example, from the deep red (meaning the extreme negative grade) through green (indicating a neutral value), and yellow (indicating extreme positive value). Between these clear colors, shades of colors can be used, which will adequately map different states of assessment intensity.

In case of evaluated characteristics concerning the effects of the QMS implementation identified as "business management", nine pairs of antonyms have been defined (see Table 2). 
Table 2

An Assessment's Questionnaire of the Effects of Business Management

\begin{tabular}{|l|l|l|l|l|l|l|l|l|l|}
\hline \multicolumn{1}{c}{$\begin{array}{c}\text { Characteristics } \\
\text { Activities... }\end{array}$} & \multicolumn{2}{|c|}{$\begin{array}{c}\text { Grades: the QMS implementation effects } \\
\text { for enterprise management group }\end{array}$} & \multicolumn{2}{c|}{$\begin{array}{c}\text { Characteristics } \\
\text { Activities... }\end{array}$} \\
\cline { 2 - 6 } & -3 & -2 & -1 & 0 & 1 & 2 & 3 & \\
\hline Effective activities & & & & & & & & Ineffective \\
\hline Not-improving management & & & & & & & & Improving management \\
\hline Reducing risk of the action & & & & & & & & Increasing the risk \\
\hline Ineffective activities & & & & & & & & Effective \\
\hline Enabling comparison of the effects & & & & & & & & Lack of possibility of the effects comparison \\
\hline Limiting efficiency & & & & & & & & Improving efficiency \\
\hline Consistent with the requirements & & & & & & & & Inconsistent with the requirements \\
\hline Improving effectiveness & & & & & & & & Limiting effectiveness \\
\hline Inflexible response to market changes & & & & & & & & Flexible response to market changes \\
\hline
\end{tabular}

Note. Source: Own study.

Transition phase is very difficult, since all the efforts should be made to reflect the nature of characteristics defined in the original statement. In such a way, their final sound could clearly express the contents of the original. Assessed are following characteristics: the management effectiveness, the level of improvement, the impact on the risk, productivity, efficiency, effectiveness, flexibility, compliance with the law, and representing benchmark of its own results over time.

For characteristics concerning organization of the activities in the enterprise, 15 pairs of antonyms have been defined (see Table 3). Assessed are following activities: (not)improving functioning of the organization, (dis)facilitating communication within the company, qualitatively (un)stable, (dis)transparently organized, (not)focused on improvement, (not)involved in the integration, (un)stable, (un)supervised, (non)complex resource management, a skill(less) problem solving, (dis)ordering documentation, (not)making decisions based on facts, (not)saving time, and (not)showing understanding of the impact of the environment on the organization.

Table 3

An Assessment's Questionnaire Concerning Organizing Activities

\begin{tabular}{|l|l|l|l|l|l|l|l|l|}
\hline \multicolumn{1}{c|}{$\begin{array}{c}\text { Characteristics } \\
\text { Activities... }\end{array}$} & \multicolumn{2}{c|}{ Grades: concerning organizing activities } & \multicolumn{2}{c|}{$\begin{array}{c}\text { Characteristics } \\
\text { Activities... }\end{array}$} \\
\hline & -3 & -2 & -1 & 0 & 1 & 2 & 3 & \\
\hline Hampering functioning & & & & & & & & Improving functioning \\
\hline Communicative & & & & & & & & Uncommunicative \\
\hline Qualitatively unstable & & & & & & & & Qualitatively stable \\
\hline Transparently organized & & & & & & & & Dis-transparently organized \\
\hline Indifferent to the improvement & & & & & & & & Improvement directed \\
\hline Open to integration & & & & & & & & Indifferent to integration \\
\hline Unstable & & & & & & & & Stable \\
\hline Supervised & & & & & & & & Unsupervised \\
\hline Imprecise & & & & & & & & Partially managing the resource \\
\hline Complex managing the resource & & & & & & & Skilful problem solving \\
\hline Skill less problem solving & & & & & & & & Disordering documentation \\
\hline Ordering documentation & & & & & & & & Making decisions based on facts \\
\hline Not making decisions based on facts & & & & & & & & Wasting time \\
\hline Saving time & & & & & & & & $\begin{array}{l}\text { Understanding of the impact of the } \\
\text { environment on the organization }\end{array}$ \\
\hline $\begin{array}{l}\text { Lack of understanding of the impact of } \\
\text { the environment on the organization }\end{array}$ & & & & & & & & \\
\hline
\end{tabular}

Note. Source: own study. 
In case of financial aspects, following assessment elements have been distinguished (see Table 4), concerning analysis the level of costs, sales, profitability, and profits, which indirectly result from the adopted and implemented pro-quality standards.

Table 4

An Assessment's Questionnaire of the Financial Aspects

\begin{tabular}{|l|l|c|c|c|c|c|c|l|}
\hline \multicolumn{1}{c}{$\begin{array}{c}\text { Characteristics } \\
\text { Activities... }\end{array}$} & \multicolumn{6}{|c|}{ Grades: effects of the QMS implementation concerning financial aspects } & \multirow{2}{*}{$\begin{array}{c}\text { Characteristics } \\
\text { Activities... }\end{array}$} \\
\cline { 2 - 8 } & -3 & -2 & -1 & 0 & 1 & 2 & 3 & \\
\hline Rationalizing costs & & & & & & & & Irrationalizing costs \\
\hline Depreciating sales & & & & & & & & Increasing sales \\
\hline Increasing profitability & & & & & & & & Depreciating profitability \\
\hline Depreciating profits & & & & & & & & Increasing profit \\
\hline
\end{tabular}

Note. Source: Own study.

As indicated by the respondents, another important thematic group is the competitors. Seven major groups of antonyms are mentioned here. Rated are activities that have an impact on: the increase/decrease of the company's competitiveness in the market, creating image of the company, the level of tendering, adapting to international standards, the level of value and attractiveness, level of reliability, and pro-quality involvement of employees of the company (see Table 5).

Table 5

Competition Assessment Questionnaire

\begin{tabular}{|l|l|l|l|l|l|l|l|l|}
\hline \multirow{2}{*}{$\begin{array}{c}\text { Characteristics } \\
\text { Activities... }\end{array}$} & $\begin{array}{c}\text { Grades: effects of the QMS } \\
\text { implementation with regard } \\
\text { to competition }\end{array}$ & \multicolumn{2}{c|}{$\begin{array}{c}\text { Characteristics } \\
\text { Activities... }\end{array}$} \\
\hline & -3 & -2 & -1 & 0 & 1 & 2 & 3 & \\
\hline Increasing competitiveness in the market & & & & & & & & Depreciating competitiveness in the market \\
\hline Deteriorating image of the company in the market & & & & & & & & Improving image of the company in the market \\
\hline Improving the ability of tendering & & & & & & & & Deteriorating the ability of tendering \\
\hline Lack of adaptation to international standards & & & & & & & & Adaptive to international standards \\
\hline $\begin{array}{l}\text { Increase of the value and attractiveness of the } \\
\text { company in the market }\end{array}$ & & & & & & & $\begin{array}{l}\text { Atrophy of the value and attractiveness of the } \\
\text { company in the market }\end{array}$ \\
\hline Lowering reliability of the company & & & & & & & & Increasing reliability of the company \\
\hline Increasing pro-quality involvement of the company & & & & & & & & Lowering pro-quality involvement of the company \\
\hline
\end{tabular}

Note. Source: Own study.

The effects of the QMS implementation are of great importance in the light of staff activity (see Table 6).

Table 6

An Assessment's Questionnaire Concerning Employees

\begin{tabular}{|l|l|l|l|l|l|l|l|l|l|l|}
\hline \multirow{2}{*}{$\begin{array}{c}\text { Characteristics } \\
\text { Activities... }\end{array}$} & \multicolumn{6}{c|}{$\begin{array}{c}\text { Grades: effects of the QMS } \\
\text { implementation with regard to } \\
\text { employees }\end{array}$} & \multicolumn{2}{c|}{$\begin{array}{c}\text { Characteristics } \\
\text { Activities... }\end{array}$} \\
\cline { 2 - 5 } & -3 & -2 & -1 & 0 & 1 & 2 & 3 & \\
\hline Increasing labour productivity & & & & & & & & Decrease of labour productivity \\
\hline Decreasing employees' motivation & & & & & & & & Increasing employees' motivation \\
\hline Increasing level of self-satisfaction of the work & & & & & & & & Decreasing level of self-satisfaction of the work \\
\hline Decreasing awareness of employees & & & & & & & & Increasing awareness of employees \\
\hline
\end{tabular}

Note. Source: Own study. 
They affect the level of: labor productivity, employees' motivation, employees' level of self-satisfaction, and awareness in the range of the QMS effects and their impact on the internal and external environment of the organization. The last presented, but not less important is the aspect of assessment of the QMS implementation effects to the organization from the point of view of potential and existing clients (see Table 7). Among evaluated characteristics distinguished were: the level of clients' satisfaction, compatibility with all the QMS standards, and the level of confidence in the quality and safety of offered products.

Table 7

An Assessment's Questionnaire Concerning Potential and Existing Clients

\begin{tabular}{|l|l|l|l|l|l|l|l|l|}
\hline \multirow{2}{*}{$\begin{array}{c}\text { Characteristics } \\
\text { Activities... }\end{array}$} & \multicolumn{6}{c|}{$\begin{array}{c}\text { Grades: effects of the QMS } \\
\text { implementation concerning clients }\end{array}$} & \multicolumn{2}{c|}{$\begin{array}{c}\text { Characteristics } \\
\text { Activities... }\end{array}$} \\
\cline { 2 - 9 } & -3 & -2 & -1 & 0 & 1 & 2 & 3 & \\
\hline Increasing satisfaction & & & & & & & & Decreasing satisfaction \\
\hline $\begin{array}{l}\text { Biased evidence that the organization } \\
\text { operates in accordance with the QMS }\end{array}$ & & & & & & & & $\begin{array}{l}\text { Vide objective evidence that the organization } \\
\text { operates in accordance with the QMS }\end{array}$ \\
\hline $\begin{array}{l}\text { Increasing confidence in the quality and } \\
\text { safety of products }\end{array}$ & & & & & & & & $\begin{array}{l}\text { Decreasing confidence in the quality and } \\
\text { safety of products }\end{array}$ \\
\hline
\end{tabular}

Note. Source: Own study.

After the analysis of partial questionnaires completed by the respondents (see Tables 2-7), a model of (dis)advantages for the assessment of the QMS implementation effects in the structures of the organization can be drawn (see Table 8). A profile created in this way will be a real and useful preparation tool for many entrepreneurs for the process of the QMS implementation in organization. They will be able, though the benchmark analysis, to prepare in an optimal way—reducing the risk and costs of mistakes.

Completion of an assessment's questionnaire consists in introducing subjectively by the respondent an assessment by marking the importance in accordance with the adopted scheme (on a scale of -3 to 3 ). However, it is worth noting that given assessments concern only the observations of the respondents in the range of effects of the QMS implementation to the organization observed by them. One can therefore consider to introduce dual questionnaire, the construction of which will be identical, except that evaluations are observations and expectations with respect to the effects of the implemented QMS. It is about the application of logic known from the works of Parasuraman, Zeithaml, and Berry $(1985 ; 1988 ; 1994)$. In an exemplary questionnaire (see Table 8), the results for the expectations and perceptions of the respondents have been shown in the range of the QMS implementation effects in the structures of the organization.

Table 8

Summary of the Results of Partial Questionnaires

\begin{tabular}{|l|l|}
\hline \multicolumn{2}{|c|}{ Assessment model (dis)advantages of the QMS implementation } \\
\hline (Dis)advantages group: & The effects of business management \\
\hline Size of organization (tick the appropriate): & Micro, small, medium, large, international \\
\hline Type of business (tick the appropriate): & Services, trade, manufacturing, other... what kind of? \\
\hline The legal form of organization (tick as appropriate): & $\begin{array}{l}\text { Company: Ltd., joint stock, general partnership, limited partnership, civil } \\
\text { individual economic activity other... what kind of? }\end{array}$ \\
\hline Additional comments: & \\
\hline Date of assessment: & \\
\hline $\begin{array}{l}\text { Name and surname of the person conducting the } \\
\text { assessment: }\end{array}$ & \\
\hline
\end{tabular}


(Table 8 continued)

\begin{tabular}{|c|c|c|c|c|c|c|c|c|}
\hline \multirow{2}{*}{\multicolumn{2}{|c|}{ Evaluation characteristics }} & \multicolumn{7}{|c|}{ Characteristics assessment } \\
\hline & & \multirow[t]{2}{*}{-3} & \multirow{2}{*}{$\begin{array}{r}-2 \\
\vdots\end{array}$} & \multirow[t]{2}{*}{-1} & \multirow{2}{*}{0} & \multirow{2}{*}{$\begin{array}{r}1 \\
-\end{array}$} & \multirow{2}{*}{2} & \multirow[t]{2}{*}{3} \\
\hline 1. & & & & & & & & \\
\hline 2. & & & $\because$ & & $<$ & & & \\
\hline 3. & & & & 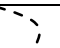 & & & 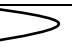 & \\
\hline$\ldots$ & & & & $\because$ & & $>$ & & \\
\hline$n$ & & & & & $\cdots$ & & $=$ & \\
\hline \multicolumn{9}{|c|}{$\begin{array}{l}\text { Legend to scale: (3) definitely yes (extremely positive); (2) yes; (1) rather yes; (0) I } \\
\text { no; }(-2) \text { no; }(-3) \text { definitely no (extremely negative) } \\
\text { semantic profile of characteristics according to expectations of respondents } \\
\text { semantic profile of characteristics according to observations of respondents ------- } \\
n: n \text {-th characteristic }\end{array}$} \\
\hline
\end{tabular}

Note. Source: Own study.

In such statement any possible difference in the assessments is visible. Besides, the contrast among the assessments of respondents might be captured easily.

\section{Conclusions}

Carried-out analysis of the information provided by the CBs in the context of defined hypotheses shows that the records located in their websites concern (dis)advantaged resulting from implementation of QMS require supplementation. On the website of Polish CBs accredited by the PCA, there is no comprehensive information on the (dis)advantages of the quality management system implementation. Therefore there are no considerations on:

- Causes ineffectively carried out by the implementation of the QMS;

- The cost of time and capital investment in the preparatory, executive, and pro-implementation processes;

- Labor costs associated with hiring additional staff with appropriate skills or the cost of employee involvement in additional responsibilities (e.g., costs of supervision);

- Preparation costs such as staff training, expertise, investment, and organizational consultation;

- Costs associated with the transformation of the company's organizational structure;

- Investment costs;

- Potential risks (resulting, for example, from the routinely carried out by individuals activities, lack of commitment, lack of accountability for taken actions);

- Disturbances or incorrectness that may occur during the process of the QMS implementation in the organization.

In this situation, in order to enable the development of an objective and at the same time comprehensive set of characteristics describing the QMS implementation effects in the structure of the organization, this article proposes the use of an assessment's questionnaire using the SD (Hys \& Hawrysz, 2012). For characteristics forming a set selected as a result of carried-out analysis of the substantive content of websites accredited by the PCA and CBs in Poland, an assessment's questionnaire has been proposed. The questionnaire contains a set of 42 antonyms for the characteristics identified in the study of websites of CBs. With regard to its clarity, the questionnaire has been divided into six parts. The division results from the thematic groups developed in the basic study. The final result of the work is a proposition of a questionnaire called an assessment model of (dis)advantages of the QMS implementation. Practical implementation of this tool may be helpful in defining 
and communicating reliable information to potential clients in the range of (dis)advantages resulting from the QMS implementation to the organization. Carried-out analysis is merely a beginning to deeper research problems, which means that the SD will be used by the author for further research.

\section{References}

Babbie, E. (2003). The practice of social research. Warsaw: PWN.

Bielecki, J. (1986). Selected aspects of psychology. Warsaw: Publ. ATK.

Brzeziński, J. (2005). Methodology of psychological research. Warsaw: PWN.

Giddens, A. (2004). Sociology. Warsaw: PWN.

Gołaszewska, M. (1964). Research on the attitudes functions. In Z. Żarnecka (Ed.), Philosophical sketches as a gift for Romano Ingarden. Cracow: PWN.

Hawrysz, L., \& Hys, K. (2013). Process-oriented management in public and private sector. China-USA Business Review, 12(9), 903-910.

Hilgard, E. R. (1967). Introduction to psychology. Warsaw: PWN.

Hys, K. (2013a). Semantic profile as a tool for assessment of competence public sector workers. Proceedings from MMK 2013.

Hys, K. (2013b). Evaluation of public sector workers for assistance method of mystery shopping. Proceedings from the 2nd Virtual International Conference on Advanced Research in Scientific Areas (ARSA-2013). Slovakia.

Hys, K., \& Hawrysz, L. (2012). (Dis)advantages of quality management systems in the light of credited certification bodies in Poland. In E. Skrzypek (Ed.), Integration in management (pp. 197-209). Lublin: University of Maria Curie-Skłodowska.

Kowalczyk, J., Jabłoński, A., \& Wawak, S. (2013). Guide of the quality management system implementation conforming to ISO 9001. Retrieved from http://www.humanms.pl

Mądrzycki, T. (1977). Psychological regularities of attitudes’ development. Warsaw: Educational and pedagogical Publ.

Mika, S. (1981). Social psychology. Warsaw: PWN.

Newcomb, T. M., Turner, R. H., \& Converse, P. E. (1970). Social psychology. Warsaw: PWN.

Nowak, S. (1973). Theories of behavior. Warsaw: PWN.

Obuchowski, K. (1972). Psychology of human aspirations. Warsaw: PWN.

Osgood, C. E., Suci, G., \& Tannenbaum, P. (1957). The measurement of meaning. Urbana: University of Illinois Press.

Parasuraman, A., Zeithaml, V. A., \& Berry, L. L. (1985). A conceptual model of service quality and its implication. Journal of Marketing, 49(4), 41-50.

Parasuraman, A., Zeithaml, V. A., \& Berry, L. L. (1988). SERVQUAL: A multi-item scale for measuring consumer perceptions of the service quality. Journal of Retailing, 64(1), 12-40.

Parasuraman, A., Zeithaml, V. A., \& Berry, L. L. (1994). Reassessment of expectations as a comparison standard in measuring service quality: Implications for future research. Journal of Marketing, 58, 111-124.

PN-EN ISO 9001:2009. (2009). Quality management systems-Requirements. Warsaw: PKN.

PN-EN ISO/IEC 17000:2006. (2006). Conformity assessment-Vocabulary and general principles. Warsaw: PKN.

PN-ISO 10014:2008. (2008). Quality management-Guidelines for realizing financial and economic benefits. Warsaw: PKN.

Prężyna, W. (1967). The concept of attitude in psychology. Philosophical Annuals XV (Roczniki Filozoficzne), 15(4), 25-38.

Prężyna, W. (1975). Self-image and the intensity of religious attitude. Philosophical Annuals XXIII (Roczniki Filozoficzne), 23(4), $5-25$.

Stoner, J. A. F., Freeman, R. E., \& Gilbert, D. R. Jr. (2001). Management. Warsaw: PWE.

Studying the impact of the ISO 9001 implementation on the competitiveness of the company in 2010. (2013). Retrieved from http://qbusiness.pl/uploads/Raporty/pbonlineiso.pdf 